\title{
Research on application of logistics information service platform based on mobile terminal
}

\author{
Wen-Dong Zhao ${ }^{\dagger}$, Fen-Fen Li, You-Dong Zhang \\ Huaiyin Institute of Technology
}

\begin{abstract}
This paper analyzes the problems existing in the small and medium logistics enterprises, and points out that the small and medium logistics enterprises should reduce the logistics cost effectively through the cooperation, mutual aid and informatization in the development of the logistics enterprises. On this basis, the existing problems of logistics information service platform are analyzed deeply. At last, the information service system based on mobile terminal is designed and implemented for vehicle transportation industry based on synergetic theory. The result shows that the information service system based on mobile terminal can close the masses of users in the logistics industry and the service they need to strengthen the connection between the small and medium enterprises, and effectively carry out the cooperation and mutual help among the enterprises and reduce the logistics cost of the small and medium enterprises.
\end{abstract}

Keywords: Intelligent terminal; Logistics information service; Collaborative theory; APP

\section{1 Introduction}

With the globalization of markets and the increasingly fierce competition in the market, the logistics as the third profit source of enterprises more and more attention, the logistics cost is an important factor in the impact of the price of their products. Due to the limitation of capital, technology, talent and environment, the logistics management level is low, there is a lack of effective integration of logistics information and low market adaptability, resulting in low efficiency of logistics and high cost, which restricts the rapid development of small and medium enterprises, logistics cost of enterprises and foreign developed countries there is still a big gap [1].

Since China's logistics industry started relatively late generally, especially small and medium logistics enterprises in the development is still in its infancy, in the development process is mainly faced with the following issues.

Unreasonable allocation of resources. Most small and medium logistics enterprises are transformed from the traditional transportation enterprises and warehousing enterprises, the service function is not perfect; it is difficult to carry out integrated logistics services, at a disadvantage in the competition [2]. Although these enterprises have a certain amount of logistics resources, but their 
own way, making the scattered resources, the utilization rate is low, causing a lot of waste.

Business coordination ability is poor. As the logistics activities between enterprises did not form a smooth logistics chain, inventory, transportation, distribution and other logistics links are disconnected from each other, poor coordination, unable to form a mutually cooperation logistics chain, thus weakening the market competitiveness of enterprises [3].

The logistics of small and medium enterprise information lag. Because of the lack of effective integration of logistics information between enterprises, hindered the timeliness and accuracy of information exchange between enterprises, affecting the speed of response to customer demand.

Logistics socialization, low degree of marketization. Many enterprise logistics is still dominated by self-logistics, virtually restricting the development of the third party logistics enterprises. From the production and processing to storage and transportation, distribution and distribution, business habits to seek self-logistics.

Thus, small and medium logistics enterprises in the development process there are many problems, it is difficult to form their own core competitiveness, which in the market competition in a disadvantageous position. Therefore, this paper studies the logistics information service platform for mobile terminals based on synergetic theory, provides services for small and medium logistics enterprises, improves the information exchange ability of enterprises in logistics activities and ultimately improves the logistics operation ability of small and medium enterprises and reduces the logistics cost of finished products. And enhance the price competitiveness of production enterprises, collaborative theory [4]. So research based on collaborative theory logistics information service platform for mobile terminals, provide services formally and medium logistics enterprises, improve the information exchange ability of enterprises in logistics activities, and ultimately enhance the logistics capacity of small and medium enterprises to reduce the cost of logistics in finished products to enhance the competitiveness of production enterprises price.

Through visits and surveys, we can understand that the domestic small and medium logistics enterprises in the business are independent operation, the lack of necessary cooperation. The operation of the market of freight cars, the property generally have the following conditions: large transport company owned, small and medium-size transport company owned, partnership or sole proprietorship and affiliated vehicles [7]. The affiliated vehicles, partnership, sole proprietorship, are basically person in operation, this part accounted for most of the market. In addition, due to some companies in the management of the demand, there are still a number of transport companies owned vehicles, 
contracted to lease to the driver in the form of the situation. The current situation of property rights, market prices caused by the confusion of the system and information asymmetry, malicious competition prevails, individual owners in the possession of sources or sources of information with companies and people to suppress, get the price is the final price of the layers of exploitation. Another situation is a more common, such as a driver in the enterprise will reach the destination of the goods, if there is no other sources of return, he is likely to return empty.

The reasons for the above situation, is mainly caused by information asymmetry. Responsible for the transport of drivers, most of the time in the transport of goods on the road, to reach the destination, the logistics cannot understand the information at that time. Therefore, the study of mobile terminal based on the application of logistics information platform for the logistics industry to provide services, especially the small and medium logistics enterprises.

\section{The development of logistics information service platform status and trends}

\subsection{The development status of logistics information service platform}

At present, the market there have been a lot of information services for the logistics industry platform, the number continues to increase, but there are no products in the domestic, to like a BAT company could dominate the world. The main reason is the founder of the platform cannot understand logistics platform should provide what kind of service.

Internet technology companies to create the logistics information publishing platform and APP, because living in the forefront of science and technology, the Internet has the deepest understanding, so the current Internet technology company is the largest operator of freight class APP. It is understood that the industry's first freight APP - goods online, is the development of Internet Technology Company. However, due to Internet technology companies on the logistics industry management methods and operational processes of the lack of knowledge, despite its strong scientific and technological capabilities, but they developed the practical applicability of freight APP is not very strong, cannot meet the freight industry operational needs.

Then there is the WWW services of professional freight or logistics website are also introduced for mobile terminal APP. These companies have gathered a certain amount of user base, such as the logistics of the logistics company's APP. These companies understand the needs of the logistics industry more in-depth research and development in science and technology have some advantages, but 
because there is a strong profitability purposes, therefore, this kind of freight forwarding APP, the number of users is limited, and developing power shortage.

\subsection{Development trend of logistics information service platform}

With the development of information technology, and the popularity of mobile intelligent terminals, the future will certainly is a vehicle information service based on mobile terminal APP services. Through mobile terminal APP, can participate in the market of all types of users and service breakthrough the limitation of time and space, real-time and convenient, which changes the existing logistics market information asymmetry phenomenon, improve the operation efficiency of the whole market, resulting in a huge market value and generate a new market opportunities for market participants, as well as production enterprises to reduce the logistics cost of the products.

This paper mainly studies the vehicle logistics transportation market, because it involves the face of the more widely. Through the investigation and research, we deeply understand the information platform of vehicle transportation market and mobile terminal APP application, due to the popularity of smart phones, giving impetus to the development of intelligent terminal APP, though they can easily connect the user and the service of the logistics industry was closely. The user here refers to all the people involved in the logistics market, including truck drivers, auto repair personnel, logistics business, industry management, insurance and financial services personnel, and other people dependent on the survival of the market. "Service" refers to the various types of personnel to provide services for logistics market, respectively, including vehicle transportation services, auto repair services, supply of goods information to provide services, vehicle management services, insurance and financial services, etc.

\section{Design of Logistics Information Service System Based on Mobile Terminal}

Based on the mobile terminal of the vehicle logistics APP is for the vehicle transportation market to provide services, and its functional design must be able to adapt to industry characteristics, for the vehicle transportation industry to provide services in line with practical application. Such as positioning, path calculation, search and information dissemination and instant messaging and other functions. Simply put, the user just pick up the phone, you can easily find the information they want, and provide online communication and exchange for the two sides to contribute to the business to help. As for vehicle transportation market to provide information service platform or mobile terminal APP, their 
commercial value is for the user in the logistics industry and services provide a communication platform, on both sides of the business process and business value, finally can also get profits [5].

According to statistics released by the transport sector, the total number of freight vehicles nationwide reached 2300 million, with the qualifications of the drivers of more than 3,000 million people. According to the latest report of enterprise data, the existing manufacturing enterprises 7.5 million, 5.2 million trade enterprises, according to China Federation of Logistics and Purchasing statistics, the registered logistics enterprises 800,000, the total cost of logistics 12 trillion. Therefore, the design and development of information platform based on mobile terminals has a huge market prospect.

\subsection{The function of the logistics information service system based on mobile terminal demand}

Through to the surrounding medium and small logistics company to visit and survey, and the domestic and foreign existing logistics information service platform, the basis of analysis and research in combination with the application requirements of small and medium logistics enterprises, we preliminary design of the logistics information service system based on mobile terminal functional requirements.

1) Before the system design, we must first clear system in the service for who, who also is the final user, logistics information service based on mobile terminal APP is mainly used to connect all kinds of personnel and services in the logistics industry, therefore, it is the service object of the logistics industry in all types of users, as well as the vehicle transportation services.

2) Secondly, we need to understand what services in the system, to give a specific range of services. Vehicle transportation industry related services related to a wide range of vehicle transportation information services, auto repair, driver recruitment, insurance services, car sales and financial services, vehicle maintenance and annual inspection services.

3) Thirdly, it is determined that the mobile terminal APP provides four main functions for the end user.

Basic functions, vehicle, cargo information release and query (platform), vehicle, business or online user positioning, ranging function and online chat.

Auxiliary function, according to the type of user registration, a reasonable allocation of authority. The users can evaluate the services provided.

Function of the third party, including auto repair, pilot recruitment, insurance services, car sales and financial services, vehicle maintenance, careful service, etc. 
4) The page layout, mainly according to the user's habits, the system function and reasonable arrangement in the intelligent terminal on the page. Our preliminary design idea is the main screen of the APP can be divided into fluctuation two parts, the upper part designed to map area, its functions including location, search, route, service information, the lower part designed to be user communication area, its function including consulting, information, distribution, contacts.

5) Finally, the system will eventually appear in front of the user page color. The essence of page color design is the visual design, including screen allocation, color selection and function key design.

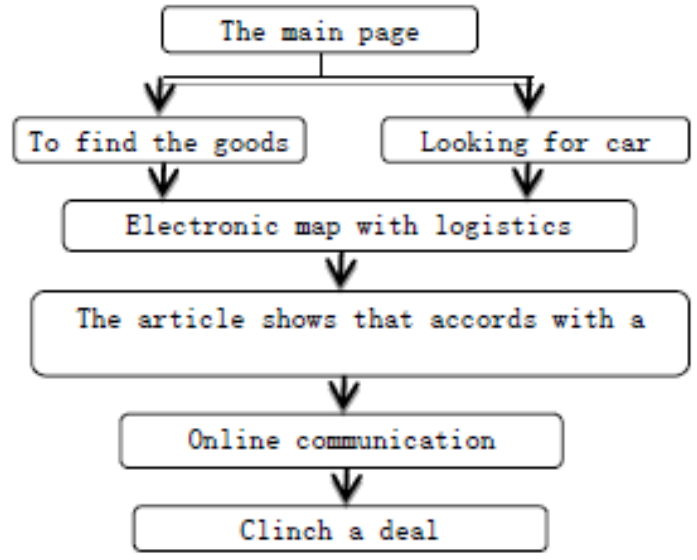

Fig. 1. system operation flow

\subsection{Mobile terminal logistics information service system operation flow}

Based on the function of the system demand, based on the principles of convenient user operation line, we combed the system operation process is shown in figure 1 . Users of the system mainly has two kinds, one is engaged in logistics transportation vehicles, 2 it is to need to ship goods owners, also is the most important service in the logistics industry. Whether truck driver looking for need to transport goods, or have sources of the owner, they all can find the information you need to through the system platform for the APP, and through the electronic map, and understand the distance between them, and based on the online communication platform, through the exchange and communication, eventually led to the business, thus achieve the purpose of service.

In order to achieve the mobile terminal based on the logistics information service APP, we must complete based on the collaborative theory of service system for the mobile terminal APP provides powerful data support, mainly to complete the following two aspects. 
Based on the Internet technology for SOA-based modern logistics information platform

The logistics system based on collaborative theory mainly includes information center management system, digital warehouse management system, collaborative marketing subsystem and mobile terminal APP system. Information platform based on digital information center management system, warehouse management system, the collaborative marketing data mining and information collection, to make logistics information synergy between all nodes, and provide decision support for the collaborative management of logistics information, they are logistics system synergy hardware, mobile terminal APP mainly provide real-time services to end users.

Based on the information system of logistics coordination and incentive mechanism design

Based on the modern logistics information platform, the modern logistics information synergy theory and the contract theory are combined to construct the information collaborative management subsystem for the logistics park and the information service center, so as to ensure the internal efficiency of the logistics center is the biggest. On this basis, the design of decision support system based on data mining, logistics were discussed from two aspects of demand and market price monitoring; realize the logistics security early warning, supporting the government and logistics association organization decisions.

\section{Based on the mobile terminal information service platform}

Based on the previous design, with the support of SOA oriented information platform [6], based on the work flow shown in Figure 1, in the realization of mobile terminal-based information service platform, we strictly in accordance with MVC layered design patterns, the integrated use of Eclipse, SQL server, and CSS technology, and according to the logic operation, the system functions will be packaged as a class, based on the architecture shown in figure 2 , respectively the presentation layer, business layer and data layer.

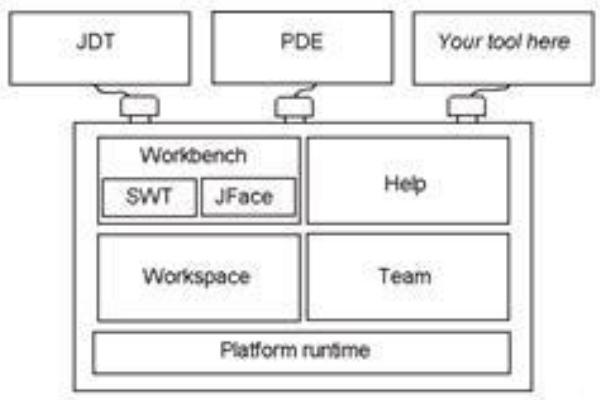

Fig. 2 Eclipse platform architecture 
We develop user-oriented intelligent terminal APP through the Java language in the presentation layer, provide the service of logistics market for each user. The business layer mainly for the presentation layer to provide specific business support, in the Android system, we mainly use the interactive device to achieve. All the data in the system comes from the data layer. Through the factory pattern of the interaction between the system and database, through the previously defined class, based on object-oriented programming method, to access the database server, for business layer provides the data source.

We achieve mobile terminal for the logistics information service APP based on the Android system and SOA service platform, run after the window is shown in figure 3. After a period of market operation, the result shows that logistics information service system based on mobile terminal basic can meet the application requirements of vehicle transportation industry. Through the application of the mobile terminal APP, the logistics industry directly to the user and the need of service. The economic benefits for the user, while also reducing the cost of logistics.

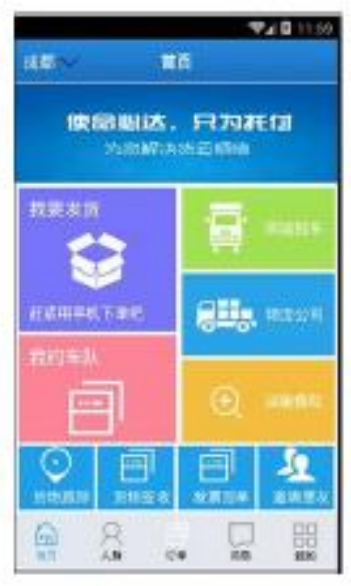

Fig. 3 mobile terminal APP

\section{Summary}

In this paper, the current situation of the development of logistics industry in our country, a detailed analysis of the present problems of the small and medium logistics enterprises, pointed out that small and medium logistics enterprises in developing should be cooperation, cooperate and realize information, can effectively reduce logistics cost. On this basis, the existing problems of logistics information service platform are analyzed deeply. At last, the information 
service system based on mobile terminal is designed and implemented for vehicle transportation industry based on synergetic theory. The results show that the information service system based on mobile terminal can close the masses of users in the logistics industry and the services they need, and strengthen the communication and cooperation among the enterprises, so as to reduce the logistics cost of the small and medium enterprises.

\section{Acknowledgments}

Project Fund: Huaian Soft Science Research Project (HAR2015007)

\section{References:}

[1]Yi Junli. The financial risk of agricultural products logistics based on AHP[M].Enterprise economy , 2012,10(8): 124- 128

[2] Chang Xinjie, Fu Zihang, Cui Feng, Chen Jie. Application situation and prospect of LNG industrial chain dynamic simulation platform [M].Chemical Engineering of Oil \& Gas, 2014.10

[3] SUN Xi. Location model construction for agricultural products logistics distribution center and its application [M].Journal of Beijing University of Agriculture, 2014, 29(2):24-29

[4] Liu Fang. Modern logistics personnel training in China Research on current situation and future development model. HLJ Foreign Economic Relations \& Trade, 2009, 3:118-121

[5] Wen-Dong Zhao. Design and Implementation of Hybrid Positioning System Based on A-GPS and RSSI. ICSIIT, 2015.12:236-242

[6] Maobao Yang. The study and design of logistics APP based on handheld mobile terminal. Intelligent computer and applications, 2015, 5(1):56-60

[7] Zhi-jiang Xu. A location querying software for vehicles based on and Android smart phone. Journal of Zhejiang University of Technology, 2013, 41(6):659-659 